\title{
The Deceptively Simple: Translating Donald Trump's Posts on Twitter into Arabic
}

\author{
Abdallah Al-Mrahleh Ula Al-Dabbagh* \\ English Department, University of Petra, Amman, Jordan
}

\begin{abstract}
This paper investigates the translation strategies that have been employed in translating Donald Trump's posts on Twitter from English into Arabic, taking into consideration Trump's use of language characterized by the excessive use of sentence fragments, colloquialism and a discourse that generally lacks cohesion. To achieve this goal, sixtyfive tweets posted in 2019, and translated by two media news agencies, namely Russia Today and Anadolu Agency are analyzed to identify the translation strategies adopted by the translators affiliated to these agencies, and to determine the impact of the strategies utilized on the target language texts. The analysis of the corpora reveals that the three most predominant translation strategies adopted by the translators of the aforementioned media outlets are, in order of importance, explicitation, omission and shifts. Overall, these strategies produce target language texts that flow smoothly and succeed in transferring the messages originally expressed in the English tweets. However, on rare occasions when unnecessary omission and unmotivated shifts are adopted, the translators of Russia Today and Anadolu Agency fail to transmit the same communicative values Trump originally conveyed to his English-speaking followers.
\end{abstract}

Keywords: Social media, Twitter, Donald Trump, Translation strategies.

DOI: $10.7176 /$ RHSS/11-22-08

Publication date: November $30^{\text {th }} 2021$

\section{Introduction}

In the past few years, politicians have come to the realization that along with the traditional media, like television and newspapers, investment in digital marketing on the social media is of paramount importance if they want to address a large audience belonging to different backgrounds. This is the case because social media enables its users to share and discuss opinions on line, and hence can directly bridge communication between politicians and their constituents and/or their supporting and opposing parties. One of the most obvious examples of political digital marketing in recent history was Donald Trump's digital campaign in 2016 which many claim won him the elections. Today, Donald Trump is still active on social media through his official accounts on Twitter, Facebook, and other social media applications, and his posts on Twitter are translated into Arabic by well-known media agencies and channel web pages such as Russia Today, Anadolu Agency, Sputniknews and Al-Jazeera, among others. These translated posts enable the Arab users of social media to understand Donald Trump's posts and become acquainted with his controversial political and social approaches to the events taking place in the United States and other parts of the world. It is, therefore, important to investigate how the messages and representations originally expressed on Trump's posts are transmitted to his Arab followers.

The present study, therefore, aims to explore how the translators of Russia Today and Anadolu Agency render Donald Trump's posts on Twitter into Arabic. It attempts to answer the following questions:

1) What are the main characteristics of Donald Trump's discourse?

2) What translation strategies do the translators of Russia Today and Anadolu Agency employ in rendering Trump's tweets from English into Arabic?

3) Do these strategies accurately transmit Trump's messages to his Arab followers on Twitter?

\section{Trump's Language on Social Media}

To be able to analyze the strategies used in translating Donald Trump's posts on social media, it is important to investigate how he uses English on Twitter. Donald Trump is considered one of the most active politicians on social media platforms whose participation on Twitter started to gain momentum after his official declaration of candidacy in 2015, when Twitter became an important political communication tool for Trump's campaign in the presidential election. Clarke and Grieve (2019) indicate that since that date Trump's Twitter activity pattern has increased significantly in terms of frequency and the level of politically charged discourse that he employs. The frequency of his tweets, as well as the content discussed and the discourse employed, have helped Trump gain a significant number of social media followers who have looked upon these tweets as official comments by the United States President.

Trump's discourse has attracted the attention of academic and non-academic researchers alike because Trump sounds refreshingly plain and forthright for the people who have grown weary of politicians using vague and complicated language to impress their listeners, to defend their ideas and to avoid criticism (Swain, 2015). The research conducted on Trump's discourse covers areas mainly associated with his use of vocabulary, sentence 
structure, incoherent fragmented sentences, repetition and colloquialism, and the results reached show that there is unanimous agreement among researchers that Trump's "presidential" linguistic style is "markedly distinct from any type of discourse we might think of as a presidential norm" (Sclafani, 2018: 14).

With regards Trump's use of vocabulary, researchers refer to the simple lexical items prevalent in his tweets, and the humiliating adjectives that he employs to criticize political personalities and events. Research conducted by Celia (2017) and Puschak (quoted in Shontell, 2016) indicate that Trump's vocabulary is "significantly simple and lacks diversity" and one syllable words make up 70\% of his tweets, while two syllable words do not exceed $20 \%$. As far as adjectives are concerned, the most common adjective in his discourse is "good," whereas other adjectives reveal a rhythm of simple opposites, such as "new" and "old," "good" and "bad," and "smart" and "dumb." Also, it is noted that Trump resorts to humiliating adjectives, like "dopey," "fraud" and "flunky" which frequently recur on his tweets to criticize his political rivals.

Trump's use of verbs is also distinct since the verbs he chooses are commonly noted in action calls that are meant to incite a specific reaction from the readers. Flores-Saviaga et al. (2018) state that Trump utilizes such verbs to inspire and motivate his supporters. Therefore, action verbs like "make" and "need" in "Make America Great" and "Here we need 1,000 because we have natural barriers," are frequently adopted to motivate his followers and ask them to support his decisions (arxiv.org/pdf/1806.00429.pdf).

Moreover, studies reveal that Trump repeats words and phrases on his Twitter posts not to create cohesion between the tweet constituents, but because repetition helps him to emphasize and strengthen the association between his supporters and himself as the president of the United States of America (Liberman, 2015). Tannen (2007) is in agreement with Liberman, for she claims that Trump resorts to repetition because when his supporters hear ideas repeatedly, these ideas "stick," and are easily remembered. Eddington (2018) discusses another feature related to Trump's use of language on Twitter. The research he conducted reveals that Trump has created his own acronyms and abbreviations that have become over time common to his social media followers. These include, but are not limited to, MAGA (Make America Great Again) and IYMI (If You Missed It). Although the "coined" acronyms and abbreviations have helped Trump save space on Twitter, excessive use of these devices in a single tweet has had a negative impact on the progression of ideas; accordingly, the production of tweets that lack cohesion.

Another characteristic of Trump's discourse that has aroused researchers' interest is associated with the structure of the sentences that appear on his posts, and which do not follow the conventions of modern political rhetoric. Swaim (2015) states that these sentences tend to be very short, and are mainly simple and compound sentences, with complex sentences rarely noted on his posts. Although simplicity is the overriding feature of Trump's sentences, there is unanimous agreement among researchers that Trump's accounts are abound with sentence fragments, and hence are "alarmingly" incoherent because the president moves quickly and unexpectedly from one thought to another, in split and unfinished sentences. In fact, Pullum (2015) succinctly describes Trump's incoherent rhetoric by acknowledging that it "bursts of noun phrases, self-interruptions, sudden departures from the theme, flashes of memory and odd side remarks" (https://languagelog. $1 \mathrm{dc}$.upenn.edu/nll?p=20490). These "unconventional" discourse characteristics are expected to create problems for translators who have shown interest in translating Trump's tweets.

Indeed, in the past few years, the translation of social media platforms, such as Facebook and Twitter has gained momentum due to the rapid increase in the number of people who use these platforms worldwide. Since social media networks were created in English, the need to translate their content into various languages became more pressing, and before long, the translators involved in this endeavor realized that they were faced with a number of challenges that had to be addressed. These challenges include, but are not limited to, the jargon and the syntax used as well as the length of the content. Consequently, the difficulties associated with replacing English social media content into other languages made the translation of these platforms fertile ground for research. The research that tackles this area covers a wide spectrum of topics ranging from the impact of social media on the translation profession, how translation is carried out in online environments and the nature of the interactions between the various groups involved in producing and receiving online translations (Desjardins, 2017; Dolmay \& Ramos, 2019; among others).

Translators who have translated Trump's posts into French, Russian, Japanese and Spanish, Chinese and Portuguese acknowledge that in the act of rendering the stylistic features prevalent in Trump's tweets into their native language they encounter a number of challenges and problems that need to be addressed. They are of the viewpoint that they can "either translate Trump exactly as he speaks and let the speakers struggle with the contentor keep the content, but smooth out the style" (Schmidt, 2017: 3). Based on these comments, it would be interesting to see how translators involved in translating Donald Trump's tweets into Arabic tackle the stylistic features that characterize the language he utilizes on Twitter.

\section{Methodology and Sample of the study}

The sample of the present study consists of 65 tweets posted on Trump's Twitter account in 2019 along with their 
Arabic translations conducted by translators affiliated to the two media agencies Russia Today and Anadolu Agency; 35 tweets were translated by Russia Today and 30 by Anadolu Agency. The choice of the aforementioned media agencies is motivated since they frequently translate Trump's tweets and have different affiliations and agendas. Russia Today is a Russian international television network founded by the Russian government, whereas Anadolu Agency is a state-run Turkish media platform. The year 2019 is selected because Donald Trump was exceptionally active on Twitter and expressed his point of view regarding a wide range of national and international topics. The 65 tweets are analyzed quantitatively in terms of the frequency of the strategies employed and qualitatively by examining examples of translations that represent each translation strategy to investigate the impact the chosen strategies have on the target texts. In the analysis, the optional translation strategies adopted by the translators are identified and analyzed; the obligatory strategies, however, are not taken into consideration since they are "automatic and offer the translator no choice" (Newmark, 1988: 85). Due to the limitations of space, selective examples are analyzed and discussed.

\section{Data Analysis and discussion}

The analysis indicates that the translators affiliated to the social media platforms selected employ the same translation strategies to translate Trump's posts, and the strategies chosen are employed in almost similar frequencies. These strategies include, in order of importance, explicitation, omission and shifts. Although other strategies, such as word-for-word translation, borrowing and foregrounding and backgrounding are adopted, they are peripheral and do not constitute trends. Tables 1 and 2, respectively show the distribution and frequency of the translation strategies adopted by the translators of Russia Today and Anadolu Agency. The results reveal that although the translators of the abovementioned news agencies have different affiliations, they resort to the same translation strategies to overcome the difficulties related to the translation of Trump's rhetoric.

Table 1. Distribution and Frequency of the Translation Strategies Used by Russia Today

\begin{tabular}{|c|c|c|}
\hline Strategy & Number of Occurrences & Percentage \\
\hline Explicitation & 99 & $58 \%$ \\
Omission & 56 & $32 \%$ \\
Shifts & 17 & $10 \%$ \\
Total & $\mathbf{1 7 2}$ & $\mathbf{1 0 0 \%}$ \\
\hline
\end{tabular}

Table 2. Distribution and Frequency of the Translation Strategies Used by Anadolu Agency

\begin{tabular}{|c|c|c|}
\hline Strategy & Number of Occurrences & Percentage \\
\hline Explicitation & 77 & $54 \%$ \\
Omission & 47 & $33 \%$ \\
Shifts & 18 & $13 \%$ \\
Total & $\mathbf{1 4 2}$ & $\mathbf{1 0 0 \%}$ \\
\hline
\end{tabular}

\subsection{Explicitation}

One of the strategies used extensively by the translators of the selected media platforms is explicitation. According to Hatim and Munday (2004: 339) explicitation "is understood as a tendency that involves adding information to the TT that is implied in the ST." In explicitation, the translator uses more words in the target language than in the source language to express the same idea which is "apparent from either the context or the situation" (Baker and Saldanha, 2009: 104). Translation scholars claim that explicitation can be achieved in a number of ways: by adding cohesive devices, by extending phrases into clauses, by including explanatory phrases, by adding footnotes, by explaining implied information, by expanding condensed information and by repeating details previously mentioned in the source text (Baker, 1992; Shuttleworth and Cowie, 1997; Blum-Kulka, 2000; Klaudy, 2001; among others).

They divide explicitation into obligatory and optional (Klaudy, 2001; Frankenberg-Garcia, 2004). Obligatory explicitation is necessary, natural and unavoidable because of the grammatical, structural and textual differences between the source and target languages. These differences oblige the translators to "bring about" elements that are implicit in the original text. Therefore, failure to explicate the elements in the target language renders it unacceptable. However, optional explicitation is associated with the translator's stylistic preferences and the cultural differences between the source and target languages. When translators adopt this strategy, they introduce information in the target text to facilitate text comprehensibility.

The analysis of the corpus shows that explicitation is the most prominent procedure adopted by the translators because Trump's language, characterized by the use of sentence fragments, sentences that lack cohesion and sentences that abound with cultural references dictate adding information to the target language texts to secure readability and the smooth flow of ideas. To overcome the aforementioned stylistic features, translators tend to "spell out" information that is implied in Trump's Tweets. The most recurrent optional instances of explicitation noted in the analyzed tweets include: (1) adding words, phrases and sentences; (2) changing pronouns into nouns; 
and (3) adding information to clarify cultural references. The following examples are illustrative of such occurrences.

Example (1a) is a tweet that was posted after the fire at Notre Dame Cathedral in Paris on April $15^{\text {th }}, 2019$ when Trump suggested using flying water tankers to put out the fire which engulfed Notre Dame Cathedral. It was translated as Example (1b) by Russia Today.

(1a) "So horrible to watch the massive fire at Notre Dame Cathedral in Paris. Perhaps flying water tankers could be used to put it out. Must act quickly."

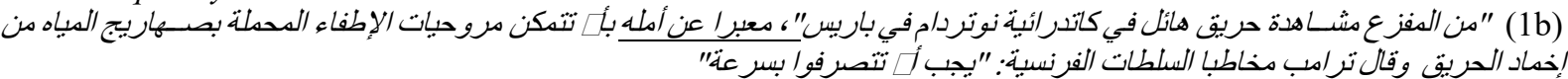

The language of the tweet in Example (1a) is representative of Trump's use of simple language in terms of construction and informality, where he favors the outspoken opinion to the "politically wise." According to Huntson (2017), this is the language of casual, unguarded talk and private language which is used among the public. Trump is addressing someone or some authority implicitly; however, the Arabic version makes explicit the identity of the entity addressed, namely the "French authorities" السلطات الفرنسية . By adding this entity, the translator ensures that the readers understand who Trump wants "to act quickly;" such a decision facilitates reading comprehensibility and does not entail extra processing effort on the readers' part.

Also, in order to "raise the tone" of Trump's words "to a more presidential level" (Berdy, 2017: 2), two phrases have been added in the translated excerpt: معبر ا عن أمله, and وقال ترامب مخاطبا السلطات الفرنسية. These two additions create cohesion between the sentences that make up the tweet. The Arabic short phrase tones "معبر ا عن أمله down" Trump's overconfidence and links between the first and the second part of the tweet. Although this addition is associated with the translator's stylistic preferences, and could have been avoided, one can argue that adding this phrase produces a more "refined" version in Arabic and endows a "human" touch on the translated text that is not expressed in the source text. Also, adding the reporting verb and the speaker's identity وقال تر امب results in a translated text that flows more smoothly since the reporting verb is "spelled out" and the speaker's identity is made explicit.

Another instance of explicitation is noted when translators transfer a pronoun into a noun to facilitate text comprehension. This is noted in Example (2a) and its translated version (2b). In Example (2a), Trump calls on Israel not to allow Democratic Ilhan Omar and Rashida Tlaib into Israel; consequently, Israel decides to bar United States congresswomen Rashida Tlaib and Ilhan Omar from entering the country ahead of a planned trip to the West Bank. The US President Donald Trump says it would "show great weakness" to allow them in. Accordingly, he posted the following twitter on August $15^{\text {th }} 2019$ :

(2a) "It would show great weakness if Israel allowed Rep. Omar and Rep. Tlaib to visit. They hate Israel \& all Jewish people, \& there is nothing that can be said or done to change their minds. Minnesota and Michigan will have a hard time putting them back in office. They are a disgrace!"

The language of this tweet characterizes Trump's offensive vocalizations against his opponents. Moreover, the tweet is an instance of the aggressive political language that he utilizes to insult his antagonists, namely Ilhan Omar and Rashida Tlaib. To refer to these two Muslim women elected to the American Congress, Trump mentions their names once and then employs the pronoun "they" to create anaphoric reference between the pronoun (they) and the entities mentioned at the beginning of the tweet (Rep. Omar and Rep. Tlaib).

In the Arabic translation, however, the translator of Russia Today repeats the proper nouns عمر وطليب although the choice of the pronoun أنهما would have produced an acceptable text in the target language. According to Aziz (1993), this instance of optional explicitation facilitates the flow of sentences in the target language because the Arab readers do not have to go back to the previous sentence to identify the pronoun referent. It is also the researchers' contention that this stylistic decision was probably taken for two reasons: (1) to overemphasize the congresswomen's names; and (2) Arabic is a language that tolerates lexical repetition.

$$
\text { (2b) }
$$

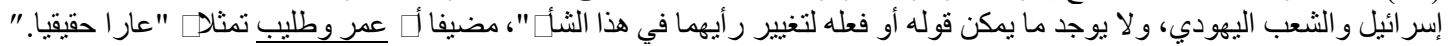

The analysis indicates that translators also revert to explicitation when cultural reference is made to entities, events and products that the Arab readers might not be aware of as noted in Example (3a) and its translation in Example (3b).

(3a) Also, I am ordering all carriers, including Fed Ex, Amazon, UPS and the Post Office, to SEARCH FOR \& REFUSE, all deliveries of Fentanyl from China (or anywhere else!). Fentanyl kills 100,000 Americans a year. President Xi said this would stop - it didn't.

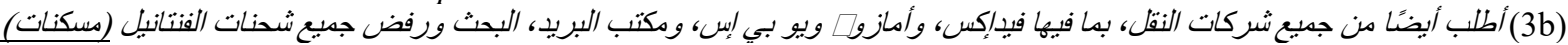

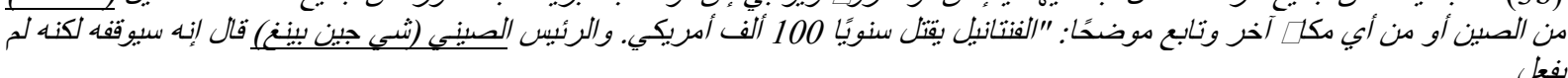

Tweet (3a) was posted by Trump during the escalating trade war between the US and China. In this tweet, the translator of the Arabic version reverts to explicitation when cultural reference is made to a product and a head of state that the Arab readers might not be familiar with. The translator of Anadolu Agency adds two explicatory 
nouns in the target language as noted in the abovementioned example: الصيني and . Adding the noun مسكنات gives more detailed information about Fentanyl so that the Arab readers become cognizant that this is a sedative product. The second instance of explicitation involves adding the implied noun " and the Chinese President's full name "شي جين بينغ". Indeed, the turbulent relations with China help Trump's American followers identify who President Xi is since his name recurs in the American press and mass media. However, adding the President's identity in the Arabic translation takes into consideration the different cultural orientations between the receivers of the source and target texts and provides the Arab readers with "additional background knowledge" about the President (Baker, 1992: 247).

It is clear that the aforementioned optional instances of explicitation do not change the meaning connotations expressed in Trump's tweets; rather, they are adopted to overcome the sentence fragments, the lack of cohesion and the cultural references that Trump produces in his tweets. This approach facilitates text comprehensibility, secures the smooth flow of sentences in the Arabic version, and conveys the message(s) originally expressed in the English tweets.

\subsection{Omission}

The second most prevalent translation strategy observed in the selected translated corpora is omission. Lacovoni (2009: 1) claims that omission signifies "dropping a word or words from the ST that do not have equivalents in the TT, or that may raise the hostility of the receptor." This procedure can be the outcome of the cultural clashes that exist between the source language and the target language.

According to Baker (1992: 40), translators use omission for a number of reasons. First, translators tend to use this strategy when the meaning conveyed by a "particular item or expression is not vital enough to the development of the text to justify distracting the reader with lengthy explanations." Second, when translators fail to find a close equivalent for a word, phrase or idea in the target language, it becomes difficult to paraphrase the meaning easily; consequently, they choose omission. Third, if a specific grammatical category in the source language does not have an equivalent in the target language, translators choose to ignore the information expressed by that grammatical category.

Dickens et al. (2002: 23) consider that omission results in "translation loss" if not carried out for "legitimate reasons." Translators, therefore, can omit information when the source and target languages use different methods to link texts together; when the information in the source text is insignificant and adding it would result in the reproduction of a target text that is unnecessarily complicated structurally; and when cultural differences exist between the source and target languages.

The translators of Russia Today and Anadolu Agency resort to omission for three reasons: (1) to delete Trump's personal views and offensive language; (2) to drop information that is repeated or insignificant to the development of the message conveyed; and (3) to omit some of the implicit performative speech acts prevalent in Trump's tweets (Examples 4, 5 and 6, respectively).

(4a) "In a letter to me sent by Kim Jong Un, he stated, very nicely, that he would like to meet and start negotiations as soon as the joint U.S./South Korea joint exercise are over. It was a long letter, much of it complaining about the ridiculous and expensive exercises. It was... also a small apology for testing the short range missiles, and that this testing would stop when the exercises end. I lookforward to seeing Kim Jong Un in the not too distant future! A nuclear free North Korea will lead to one of the most successful countries in the world!" (4b)

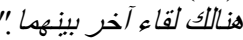

In Example (4a), Donald Trump resorts to offensive vocabulary regarding the content of the letter he received from the North Korean President. According to Trump, the letter "was a long letter, much of it complaining about the ridiculous and expensive exercises. It was...also a small apology for testing the short range missiles, and that this testing would stop when the exercises end." The Russia Today translator decides to delete the personal information provided by Trump especially that the lexical items and phraseology used disregard the protocol usually followed by presidents and heads of state (Example 4b). The translator also omits Trump's willingness to meet Kim Jung-Un and his point of view regarding the future of North Korea as a nuclear free nation when he states that "A nuclear free North Korea will lead to one of the most successful countries in the world!" This strategy was most probably adopted because the omitted information is peripheral to an Arab reader and its deletion does not negatively impact the most important message Trump wanted to convey to his followers: meeting the North Korean President. This strategy has resulted in a condensed target language text that conveys the message that can be of interest to an Arab reader.

In Example (5a) Trump uses the acronyms "AOC" and "PLUS 3" which can only make sense to an American audience familiar with American national politics.

(5a) "Rep Tlaib wants to cut off aid to Israel. This is the new face the of Democrat Party? Read the AOC PLUS 3 statements on their hatred of Jews and Israel. Check out Rep. Omar (the great people of Minnesota won't stand for this)." 


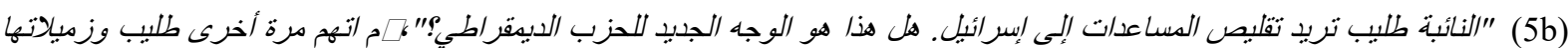

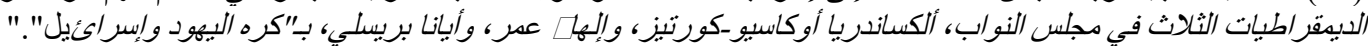

"AOC" refers to the democratic representative Alexandria Ocasio Cortez, whereas the "PLUS 3" refers to the three democratic Congresswomen, namely Ayanna Pressley, Ilhan Omar, and Alexandria Ocasio Cortez. These acronyms are deleted in the Arabic translation (Example 5b) because they are insignificant to an Arab reader and reproducing the acronyms would have affected the smooth flow of information. The translation strategy adopted in transferring this tweet into Arabic is in line with Baker's (1992: 40) viewpoint that states "if the meaning conveyed by a particular item or expression is not vital enough to the development of the text to justify distracting the reader with lengthily explanations, translators can and often do simply omit translating the word or expression in question."

The translator also deletes the last sentence of the tweet in which Trump tries to arouse negative sentiments against the Democratic Congresswoman of Arab Somali origins Ilhan Omar. It is the researchers' contention that Russia Today adopts this strategy for two reasons: this sentence does not add to the meaning of the tweet; and by deleting this sentence, Russia Today avoids offending the Arab readers.

One can say that the aforementioned instances of omission do not have a negative impact on the resultant Arabic texts; in fact, they are conducted to help in the production of target texts that transmit succinctly the most significant information originally expressed in the source language.

This end-result, however, is not achieved when the translators of Russia Today and Anadolu Agency delete the implicit performative acts that Trump employs in his tweets (Searle, 1996). Example (6a) is a tweet posted by Trump during the escalating trade war between the US and China. Trump uses a number of implicit performative acts in this tweet; these are the acts of confirming, warning, predicting and promising. Trump confirms that the US-China negotiations are faring well; warns that China would like to deal with another President to "rip off" the USA; predicts that he is going to be reelected as president; and promises as president-elect to deal with China in a "much tougher way" to negatively impact the Chinese economy. However, the translator of Anadolu Agency deletes these performative acts and produces instead a series of statements and reports. By doing so, the acts of confirming and predicting as well as Trump's forceful tone of warning and promising are nullified in the Arabic version; this end-result, which could have been avoided had the translator understood the communicative force of the performative acts implied in the tweet, produces a different message than the one conveyed to Trump's English speaking audience.

(6a) "We are doing very well in our negotiations with China. While I am sure they would love to be dealing with a new administration so they could continue their practice of "ripoff USA"(\$600 B/year),16 months PLUS is a long time to be hemorrhaging jobs_and companies on a long-shot_And then, think what happens to China when I win. Deal would get MUCH TOUGHER! In the meantime, China's Supply Chain will crumble and businesses, jobs and money will be gone!"

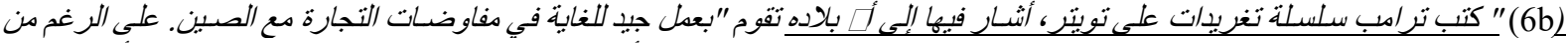

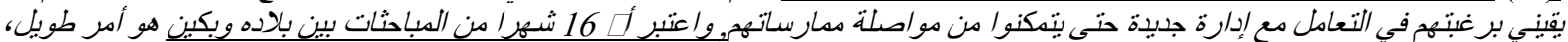

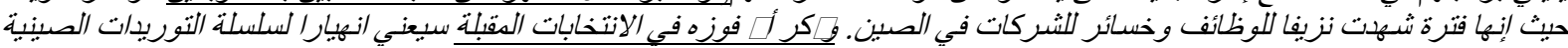

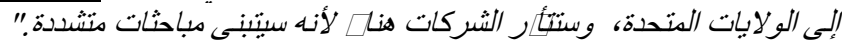

This example, and others in which performative acts are deleted, indicate that the unmotivated instances of omission can mar the intended meaning expressed in the source language text and can lead to translation loss (Dickens et al, 2002). Consequently, omission has to be applied cautiously in the process of translating Trump's tweets to avoid distorting the meaning potential expressed in the original text.

\subsection{Shifts}

Another translation strategy that is employed by the translators of the selected media agencies is shifts. Shifts are noted when some kind of alteration or adjustment emerges in the process of translating a source text into a target text; these modifications can be obligatory or optional. The former are unavoidable due to the linguistic and textual differences between the source and target languages, while the latter are "opted for by the translator for stylistic, ideological or cultural reasons" (Bakker et al., 1998: 288).

The most frequent optional shifts attested in the translation of the selected corpora are referential shifts and modifications that involve changing the passive construction to the active construction. The following examples discuss some of these shifts and the impact on the Arabic texts.

In Example (7a), Trump offers US assistance to the prime minister of New Zealand, subsequent to the deadly shooting at a pair of mosques:

(7a) "Just spoke with Jacinda Ardern, the Prime Minister of New Zealand, regarding the horrific events that have taken place over the past 24 hours. I informed the Prime Minister that we stand in solidarity with New Zealand - and that any assistance the U.S.A. can give, we stand by ready to help. We love you New Zealand!"

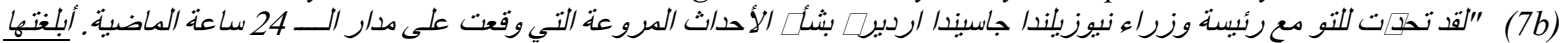

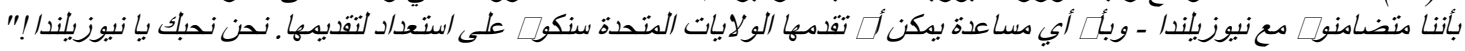


The Anadolu Agency translator transfers the noun "Prime Minister" into the connected pronoun "in the Arabic version. The translator resorts to this strategy because opting for anaphoric reference in this context does not have a negative impact on text comprehension. The pronoun, which refers to the Prime Minister of New Zealand, mentioned in the previous sentence, can be easily interpreted by recourse to the noun رئيسة وزر اء نيوزيلنداء in the preceding sentence. Although Arabic tolerates repetition, and repeating the noun رئيسة وزراء نيوزيلنداء have been acceptable, the translator realizes that the use of repetition in this context does not have a textual and/or stylistic function which gives him/her the liberty to replace the noun with the pronoun as noted in (7b).

In Example (8b), a number of shifts at the referential level are noted. The pronoun "we" in the original tweet (Example 8a) realizes the collective identity of the people and the president as one group in solidarity with each other. The translator of Anadolu Agency renders this pronoun and its connotations into بلاده, and hence suppresses the "unity" between the president and the Americans expressed in the English version.

(8a) We are doing very well with China. This has never happened to them before!

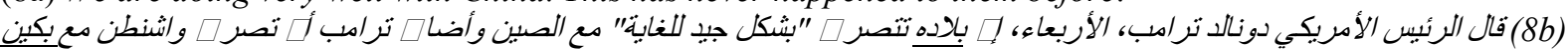

Also, the pronoun "them" in the second sentence is transferred into the noun يكين. By producing this shift, the differentiation between the collective "we" and the detached "them" is missing. Consequently, one can say that unlike the shift observed in Example (7b) which does not change the meaning relations expressed in the English tweet, the unmotivated optional stylistic shifts in Example (8b) have resulted in unnecessary changes in the meaning connotations expressed in Trump's English tweet. In fact, the meaning conveyed to the English speaking audience is transferred in a different way to the Arab readers of the tweet.

In Example (9a), Trump uses the passive voice to leave responsibility of removing the remaining 50 American soldiers from Syria unspecified which results in the "obfuscation of agency and causality" (Fairclough, 1989: 125). However, the Anadolu Agency translator chooses to use the active construction أننا سحبناهمand emphasizes the agent: the collective "we" representing the American President and his administration. Although this shift leaves no room for entity speculation and inference, it was probably carried out to produce a text that flows smoothly, and hence is easier to assimilate by the Arab readers.

(9a) Turkey fully understands that we only had 50 soldiers remaining in that section of Syria, and they have been removed, any unforced or unnecessary fighting by Turkey will be devastating to their economy and to their very fragile currency.

$$
\text { تركيا تعي جيدا أنه، كال لنا } 50 \text { جنديا في هذا الجزء من سوريا (منطقة العملبات) ، وأننا سحبناهم منذ زمن }
$$

The abovementioned shifts reveal that the motivated optional shifts attested do not hamper text comprehensibility; rather, they produce target language texts that are "transparent" by avoiding the "awkward" structure noted in Trump's tweets. Unmotivated shifts, however, produce meaning connotations that do not carry the communicative values expressed in Trump's English tweets. Accordingly, they can be considered errors that should have been avoided in the act of translation.

\section{Conclusion}

This paper has studied the translation strategies employed by the translators of Russia Today and Anadolu Agency in transferring Donald Trump's posts on Twitter from English into Arabic and investigated whether the same strategies have been adopted by the translators affiliated to the aforementioned media platforms. It has also analyzed the impact of the selected strategies on the Arabic translated tweets.

The results reveal that the translators affiliated to Russia Today and Anadolu Agency adopt the same translation strategies in the act of translating Donald Trump's tweets from English into Arabic with almost similar frequencies of recurrence. These strategies include, in order of importance, explicitation, omission and shifts, and the majority of these shifts produce texts that flow smoothly, are easy to comprehend by the Arab end-receivers, and convey the same messages expressed in the English tweets. However, it is noted that the translators of Russia Today and Anadolu Agency sometimes fail to convey the implicit performative acts originally expressed by Trump when they omit these acts and produce Arabic texts that transmit a message that is incongruent with the one Trump conveyed to his English-speaking followers. One can, therefore, say that translating Trump's simple discourse from English into Arabic is not as simple and straightforward as it may seem. Indeed, transferring some of Trump's tweets correctly into Arabic not only depends on the translators' ability to interpret Trump's language, but his rationale and ideological orientations as well.

\section{References}

Aziz, Y. (1993). “Explicit and Implicit Reference in Arabic-English Translation”, Babel, 39 (3), 129-150.

Baker, M. (1992). In Other Words: A Course Book on Translation. London \& New York: Routledge.

Baker, M. \& Saldanha G. (2009). "Norms.” In Routledge Encyclopedia of Translation Studies (2nd Edition.), ed. Mona Baker and Gabriela Saldanha, 189-193. London \& New York: Routledge.

Bakker, M., Koster, C., \& van Leuven-Zwart, K. (1998). "Shifts of Translation." In Encyclopedia of Translation 
Studies, ed. Mona Baker, 226-231. London \& New York: Routledge.

Berdy, A. M. (2017). Meester Trump Tweets in Russian. [Online] Available at https://www.themoscowtimes.com/2017/03/24/meester-trumps-russian-tweets-a57522, (accessed December 5, 2019).

Blum-Kulka, S. (1986/2000). "Shifts of Cohesion and Coherence in Translation. In The Translation Studies Reader, ed. Lawrence Venuti, 298-313. London \& New York: Routledge.

Celia, G. (2017). Trumpslation: Toward a Srategy of Translating Donald Trump's Spontaneous Speech. Glasgow: University of Glasgow.

Clarke, I. \& Grieve, J. (2019). Stylistic Variation on the Donald Trump Twitter Account: A Linguistic Analysis of Tweets Posted between 2009 and 2018. [Online] Available at https://doi.org/10.1371/journal.pone.0222062, (accessed December 5, 2019).

Desjardins, R. ( 2017). "Translation and Social Media". In Theory, in Practice and in Professional Training. London: Palgrave Macmillan.

Dickins, J., Sándor, H., \& Higgins, I. (2002). Thinking Arabic Translation: A Course in Translation Method: Arabic to English. London \& New York: Routledge.

Dolmay, M. Julie R., \& del Mar Sánchez, M. (2019). “Characterizing Online Social Translation.” Translation Studies, 12 (2), 129-138.

Eddington, M. Sean. 2018. The Communicative Constitution of Hate Organizations Online: A Semantic Network Analysis of 'Make America Great Again.' [Online] Available at https://journals.sagepub.com/doi/10.1177/2056305118790763, (accessed January 17, 2020).

Fairclough, N. (1989). Language and Power. London: Longman.

Flores-Saviaga, C., Brian, C. Keegan, \& Savage, S. (2018). Mobilizing the Trump Train: Understanding Collective Action in a Political Trolling Community. [Online] Available at arxiv.org/pdf/1806.00429.pdf (accessed March 2, 2020).

Frankenberg-Garcia, A. (2004). "Are Translations Longer than Source Texts? A Corpus-based Study of

Explicitation." [Online] Available at http://www.linguateca.pt/Repositorio/Frankenberg-+9+Garcia2004.doc, (accessed November 4, 2019).

Hatim, B. \& Munday, J. (2004). Translation: An Advanced Resource Book. London \& New York: Routledge.

Huntson, S. (2017). "Donald Trump and the Language of Populism". [Online] Available at https://www.birmingham.ac.uk/research/perspective/donald-trump-language-of-populism.aspx, (accessed March 2, 2020).

Lacovoni, A. (2009). Translation by Omission. [Online] Available at http://iacovoni.wordpress.com/2009/02/01/translation-by-omission/-, (accessed March 3, 2020).

Klaudy, K. (2001). "Explicitation”. In Routledge Encyclopedia of Translation Studies, ed. Mona Baker, 80-84. London \& New York: Routledge.

Liberman, M. (2015). Trump's incohrence. [Online] Available at https://languagelog.ldc.upenn.edu/nll/?p=44476, (accessed November 4, 2019).

Newmark, P. (1988). A Textbook of Translation. New York \& London: Prentice-Hall.

Pullum, G. (2015). Trump's Aphasia. [Online] Available at https://languagelog.ldc.upenn.edu/nll/?p=20490, (accessed March 5, 2020).

Schmidt, S. 92017). Make America Big Again? The Headache of Translating Trump into Foreign

Languages. [Online] Available at https:/www.washingtonpost.com/news/morning-mix/wp/2017/01/23/makeamerica-big-again-the-headache-of-translating-trump-into-foreign-languges, (accessed December 10, 2019).

Sclafani, J. (2018). Talking Donald Trump: A Sociolinguistic Study of Style, Metadiscourse, and Political Identity. London \& New York: Routledge.

Searle, R, J. (1970). Speech Acts: An Essay into the Philosophy of Language. Cambridge: Cambridge University Press.

Shontell, A. (2016). This one-minute long, 220-word answer given by Donald Trump proves he is the ultimate salesman. [Online] Available at https:/www.businessinsider.com/analyzing-the-way-donald-trumpspeaks-like-a-salesman-2016, (accessed December 2, 2019).

Shuttleworth, M. \& Cowie, M. (1997). Dictionary of Translation Studies. Manchester: St. Jerome.

Swaim, B. (2015). How Donald Trump's Language Works for Him. [Online] Available at https://www.washingtonpost.com/news/the-fix/wp/2015/09/15/how-trump-speak-haspushed-the-donaldinto-first-place/, (accessed February 7, 2020).

Tannen, D. (2007). Talking Voices: Repetition, Dialogue, and Imagery in Conversational Discourse.

Cambridge: Cambridge University Press.

Trump, Donald Tweets. (2019). Donald J. Trump@realDonaldTrump. (accessed December 30, 2019). 